\title{
THE GENUS ISCHNOTHYREUS \\ (ARANEAE, OONOPIDAE) IN \\ CENTRAL AMERICA AND THE WEST INDIES*
}

\section{By Arthur M. Chickering}

Museum of Comparative Zoology

The genus Ischnothyreus Simon was based upon a female from St. Vincent, B. W. I. in I89I. In I893 Simon stated that he had the species described from St. Vincent also from parts of Africa, Ceylon, Sumatra, Java and the Philippines. His identification of the male of the same species from West Africa was clearly an error as will be made clear later in this paper. The genus is now known to be widely distributed in the regions named above as well as in the Hawaiian Islands, Central America, Florida and the West Indies. Careful collecting in South America willl probably show that the genus is also widely distributed throughout much of that continent. Petrunkevitch (1929) reported the female of I. peltifer (Simon) from Puerto Rico. Miss Bryant (1940) reported the female from Cuba. In 1942 she also described the male of Dysderina antillana from St. Croix, U. S. V. I. and in 1948 reported the female of this species from Haiti. Both of these are now clearly seen to be members of the species I. peltifer (Simon). In 195 I I reported the collection of a single female of $I$. peltifer (Simon) in the Canal Zone Forest Preserve in July, 1939. Since that date a large collection of the genus has accumulated from Central America and the West Indies where I have done extensive collecting several times during the past seventeen years.

The holotypes of new species described in this paper together with my entire collection of the genus Ischnothyreus will be deposited in the Museum of Comparative Zoology, Harvard University.

Grants GB-180I and GB-5013 from the National Science Foundation have greatly aided me in extensive field work during the past four years and in my continued studies in the Museum of Comparative Zoology. In this brief paper I will simply state that I am repeating my grateful acknowledgements of aid and encouragement from the staff of the Museum of Comparative Zoology as frequently stated in numerous publications during the past many years. These acknowledgements should also be extended to Dr. W. J. Gertsch,

*Manuscript received by the editor October 16, 1867 
American Museum of Natural History together with Dr. G. Owen Evans and Mr. D. J. Clark, Dept. of Zoology, British Museum (Natural History) for the loan of valuable specimens.

\section{Genus Ischnothyreus Simon, I 893}

The type species is Ischnothyreus peltifer (Simon) by monotypy. The genus was established on the basis of a female from St. Vincent, B. W. I. and placed in the genus Ischnaspis, I891. Simon soon found that this name was preoccupied and he then changed the name of the genus to Ischnothyreus in I893. As a result of my study of the species treated in this paper I think the most important features of the genus may be stated as follows: The total length varies from nearly I.25 $\mathrm{mm}$ in males to about $2.25 \mathrm{~mm}$ in females. The body and appendages are only moderately chitinized with the exception of the male palps in contrast to such genera as Dysderina, Opopaea and Scaphiella. Carapace moderately tall; about three fourths to four fifths as wide as long; thoracic region well rounded along ventral border; much narrowed just behind PE; without any median groove or pit. Sternum more or les scutiform; quite convex; surface smooth with a moderately developed coat of hair; extended between bases of fourth coxae which are separated by at least their width and usually more than this. Eyes: six in two rows, in a compact group; AME lacking; ALE either almost in contact medially or narrowly separated; eyes of posterior row close together; posterior row either straight or slightly procurved, viewed from above (Fig. I and Fig. 2, Suman, I965); with no marked size differences. Legs: 4I23 in order of length; moderately long and slender; first two pairs with more or less conspicuous, long, ventral spines on femora, tibiae and metatarsi; trichobothria present on at least tibiae and metatarsi and on certain segments of the palps; apparently, third and fourth legs without true spines. In females the chelicerae are simple and without special modifications. In at least two species (I. peltifer (Simon) and I. omus Suman) the males have a curious knob or hook at the base of the fang (Figs. 2-3) ; the fang groove appears to have minute teeth along the margins in at least certain species (Suman, 1965, Fig. 4). The lip is simple, without special modifications. The maxillae are simple and unmodified in females but in males of certain species they are distally modified (I. peltifer (Simon), I. indressus sp. nov.). The palp in females is also simple and without special modifications but in males it has a more or less distinctively modified tarsus (Figs. 6-8) with other segments simple and unmodified except for the strong chitinization and dark brown color in contrast to the 

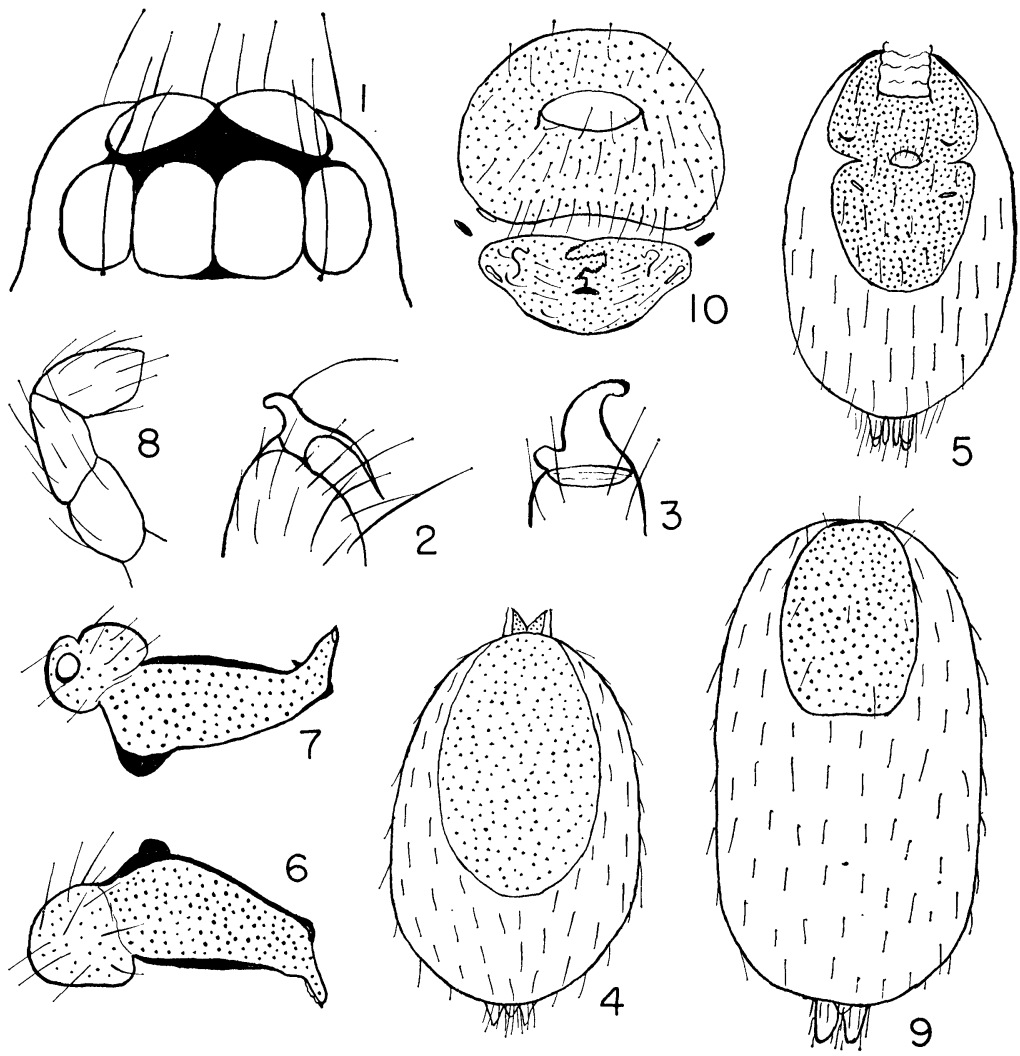

Figs. 1-10. Ischnothyreus peltifer (Simon). Fig. 1. Eyes from above. Fig. 2. Distal end of left chelicera; retrolateral view. Fig. 3. Base of left cheliceral fang in profile. Fig. 4. Abdomen of male from above. Fig. 5. Epigastric and ventral scuta of male; genital aperture; from below. Figs. 6-7. Nearly retrolateral and prolateral views of left palpal tarsus, respectively. Fig. 8. Left palpal femur, patella and tibia, nearly prolateral view. Fig. 9. Female abdomen from above. Fig. 10. Epigastric and ventral scuta of female with epigynal area.

light yellowish surrounding parts. The abdomen is ovoid; provided with both dorsal and ventral scuta (contrary to some published statements) although these may be poorly developed in certain species; in males the dorsal scutum extends about two thirds of the distance from base to posterior end but is considerably shorter in females (Figs. 4, 9); the epigastric scutum is moderately well developed in 
both sexes but the ventral scutum varies considerably in shape and, to some extent, also in size (Figs. 5, 10). In females the ventral scutum bears a more or less distinctive but obscure epigynal area showing an irregularly twisted minute canal. In the male the division between epigastric and ventral scuta is not clear but there is a genital aperture showing quite clearly. The six spinnerets are moderately well developed with no special modifications.

Key to the known males of Ischnothyreus from Central America and the West Indies

Ia. Species with a conspicuous knob at base of fang (Fig. 2) I. peltifer, $\mathrm{p}$.

Ib. Species without such a knob at base of fang as given above (browni, indressus) 2

2a. Species with a relatively long, curved, somewhat lobulate extension of the palpal tarsal bulb (Fig. 12) ....... I. browni, p.

2b. Species without such an extension of the palpal tarsal bulb as given above I. indressus, $\mathrm{p}$.

\section{Ischnothyreus peltifer (Simon)}

Figures I-IO

Ischnaspis peltifer Simon, 1891: 562. The female holotype from St. Vincent, B. W. I. is in the British Museum (Natural History), examined.

Ischnothyreus peltifer, - Simon, 1893: 298; (not male p. 299, fig. 264).

Petrunkevitch, 1911: 127; 1928: 88；1929: 66; Bryant, 1940: 266;

Roewer, 1942: 287; Chickering, 1951: 219; Bonnet, 1957: 2309.

Dysderina antillana, - Bryant, 1942: $324 ; 1948: 340$.

In view of the confusion in the literature regarding this species I have thought it desirable to select a male and a female for description from St. Vincent, B. W. I., the type locality.

Male. Total length $1.67 \mathrm{~mm}$, including extended spinnerets. Carapace $.75 \mathrm{~mm}$ long; $.57 \mathrm{~mm}$ wide opposite interval between second and third coxae where it is widest; about .3I mm tall; regularly arched from $\mathrm{PE}$ to beginning of posterior declivity which is quite steep along upper two thirds and then much less so to posterior border; surface quite smooth and shiny. Eyes: six in two rows, quite compactly arranged (Fig. I); AME lacking; posterior row occupies about $5 / 7$ of width of carapace at that level and is very slightly procurved, viewed from above. Ratio of eyes ALE : PME : PLE $=7: 7.5: 6.5$. All eyes somewhat oval in outline (long diameters always used in measurements). ALE separated only by a line; separated from PME by about $2 / 7$ of their diameter and from PLE only by a narrow line. All posterior eyes contiguous. Height of clypeus nearly equal to diameter of ALE. Maxillae: convergent; 
distal end sharply pointed and strongly chitinized; apparently also accompanied by a soft, median portion. Lip much wider than long; sternal suture procurved. Sternum: convex; smooth, without grooves as in Dysderina; with a sparse supply of stiff bristles; about as wide as long; bluntly terminated between fourth coxae which are separated by nearly I.6 times their width. Chelicerae: nearly vertical; parallel; moderately robust; fang long, slender and curiously knobbed at base (Fig. 2); fang groove without definite teeth but some specimens may have a small number of very minute denticles. Legs: 4I 23 in order of length; tibial index of first leg 12, of fourth leg 8; spines essentially as recorded by Petrunkevitch (1929) and Bryant (1942); some variations have been noted among the many specimens now available for comparison. Palp: quite unlike Figure 264 (Simon, I893) which may have been taken from a specimen of Opopaea; essentials as shown in Figures 6-8: all segments simple with no special modifications except tarsus; all segments strongly chitinized and dark brown. Abdomen: ovoid; with dorsal scutum as shown in Figure 4; division between epigastric and ventral scuta quite indefinite but genital aperture shows clearly near the center of this region. Color in alcohol: carapace yellowish in a broad central region, grayish along lateral regions from opposite palps to lower part of posterior declivity; two oval darker areas dorsolateral in position in anterior portion apparently because of colored internal parts (I. omus Suman, 1965, Fig. I). Sternum and legs yellowish with some variation. Palp: all segments from trochanter a dark brown. Abdomen: dorsal scutum light brownish; ventral and epigastric scuta yellowish, only slightly darker than regions not covered by scuta.

Female. Total length $2.2 \mathrm{I} \mathrm{mm}$, including extended spinnerets (Simon gave length of female holotype as $3.5 \mathrm{~mm}$ ). Carapace $.76 \mathrm{~mm}$ long; .64 mm wide; about .22 $\mathrm{mm}$ tall. Dorsal abdominal scutum small, reaching somewhat less than half way from base to posterior end of abdomen (Fig. 9) ; epigastric and ventral scuta essentially as represented in Figure IO; some variations in appearance of scuta have been noted among the many specimens now available for study. Dr. Petrunkevitch's description of the female from Puerto Rico (1929) may be consulted for more detail; he stated, however, in his key to the Oonopidae of Puerto Rico that the female had no ventral scuta.

Records. Several dozens of specimens were taken at Turrialba, Costa Rica, July 25-August I5, 1965. Hundreds of both sexes are in my collection from numerous localities in the Panama Canal Zone and Panama proper taken during the past fifteen years. More than 

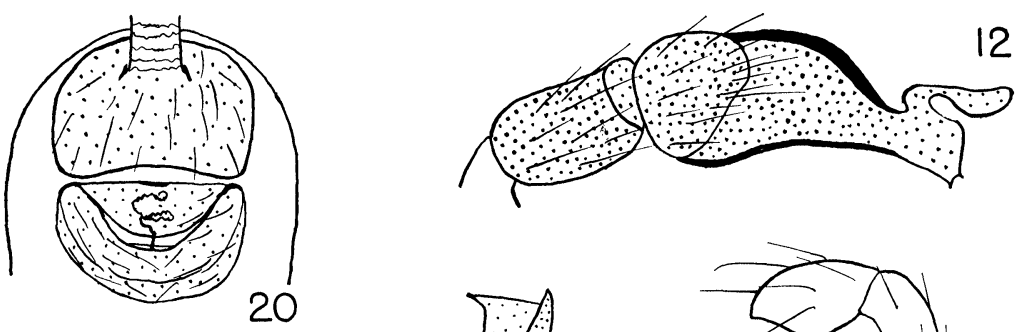

12

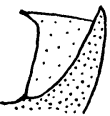

13
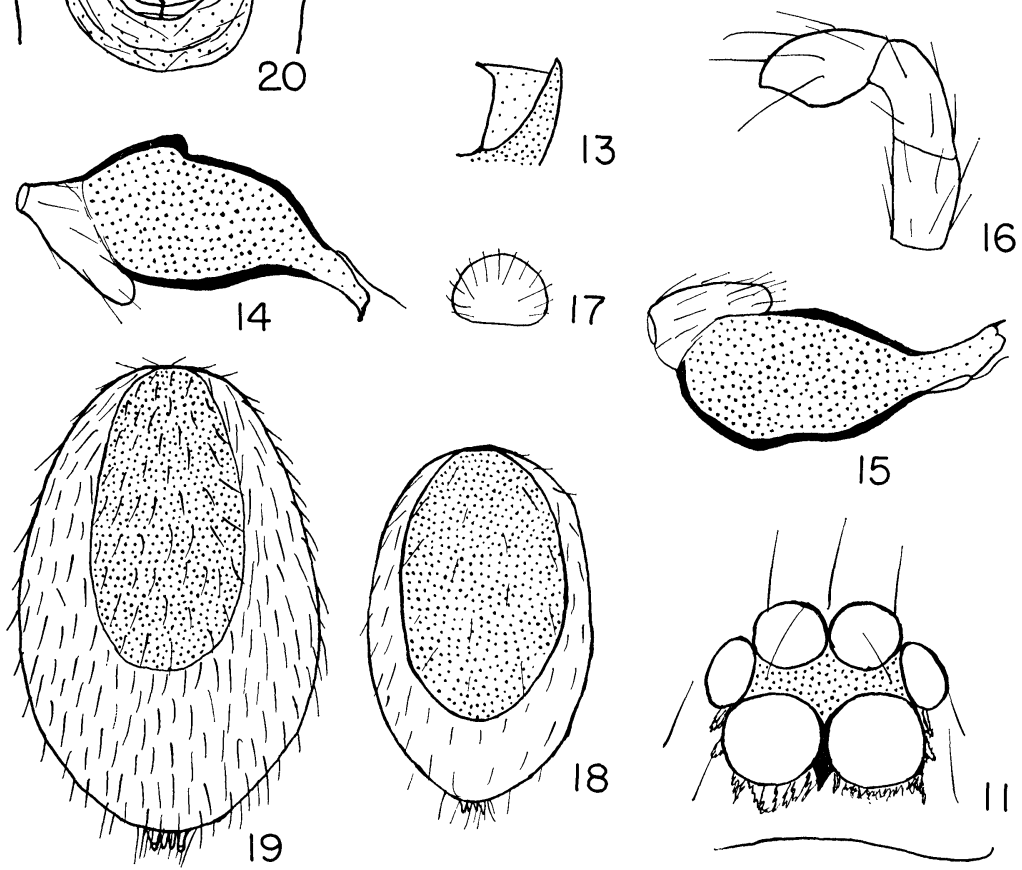

Figs. 11-20. Ischnothyreus browni sp. nov. Fig. 11. Eyes from in front. Fig. 12. Left palpal tibia and tarsus; nearly prolateral view. Figs. 13-20. Ischnothyreus indressus sp. nov. Fig. 13. Distal end of right maxilla. Figs. 14-15. Nearly retrolateral and prolateral views of left palpal tarsus, respectively. Fig. 16. Right palpal femur, patella and tibia; nearly prolateral view. Fig. 17. Genital aperture of male. Fig. 18. Abdomen of male; dorsal view. Fig. 19. Abdomen of female; dorsal view. Fig. 20. Ventral and epigastric scuta of female with epigynal area.

IOO were taken in one day at Gatun, Canal Zone and all came from hay and weed debris. In the West Indies the species has been taken in Jamaica; Puerto Rico; all three U. S. Virgin Islands; Tortola, British Virgin Islands; St. Lucia; St. Vincent; Cuba; Haiti; Curaçao and Trinidad. A male is in the collection of the Museum of Com- 
parative Zoology from Bermuda (N. A. Weber, no date) but has never been described. I did not collect this species on St. Kitts. Nevis or Virgin Gorda during my visit to these islands in the summer of I966.

\section{Ischnothyreus browni sp. nov.}

Figures I I-I 2

Holotype. The male holotype is believed to have been collected by Dr. W. L. Brown, Cornell University, in Costa Rica, Río Toro Amarillo near Guapiles, Heredia, March 1966. The species is named after the collector.

Description. Total length $1.23 \mathrm{~mm}$. Carapace $.68 \mathrm{~mm}$ long; $.55 \mathrm{~mm}$ wide opposite second coxae where it is widest; about $.37 \mathrm{~mm}$ tall; evenly arched from PE to beginning of moderately steep posterior declivity; smoothly rounded along ventral margin. Eyes: six in two rows in a compact group (Fig. II); Posterior row wider than anterior row in ratio of about $16:$ I3; viewed from above, posterior row slightly procurved but almost straight. Ratio of eyes ALE : PME : PLE = 7.5:6:6. ALE separated by a line; contiguous to PLE at one point; PME contiguous for about one fourth of their circumference and contiguous to PLE for a shorter distance. Clypeus a little higher than radius of ALE. Chelicerae do not have the knobbed fang as in I. peltifer (Simon). Maxillae appear to be essentially like those in I. peltifer (Simon). Lip appears to be simple and without special modifications. Fragility of the two males available prevents the desired close examination. Sternum quite convex; only a little longer than wide; bluntily rounded between bases of fourth coxae which are separated by I.3 times their width. Legs: 4I23 in order of length; spines on certain segments difficult to observe but apparently they closely resemble those on the legs of I. peltifer (Simon). Palp: general features typical of males of the genus; all segments except tarsus short and unmodified except for the strong chitinization; distinctive features of tarsus shown in Figure 12. Abdomen: apparently also typical of males of the genus except for the scuta which are hardly discernible with borders very indefinite; dorsal scutum appears to reach only a little more than half way from base to posterior end; genital aperture very obscure but apparently as in the two other species treated in this paper. Color in alcohol: carapace yellowish with the relatively large, oval spots, represented in figures of $I$. omus Suman, 1965 from Hawaii, darkest; ocular area with considerable black pigment, some of it in front irregularly distributed (Fig. II). Sternum, legs and all mouth parts except palps 
light yellowish with some variation. Palps conspicuously dark brown as usual in the genus. Abdomen light yellowish with poorly chitinized scuta slightly darker.

Female paratype. Total length $\mathrm{I} .43 \mathrm{~mm}$ exclusive of extended spinnerets; including extended spinnerets total length is $1.56 \mathrm{~mm}$. Carapace $.66 \mathrm{~mm}$ long; $.59 \mathrm{~mm}$ wide; about $.44 \mathrm{~mm}$ tall; otherwise essentially typical of females of the genus. Eyes: apparently essentially as in male; chitin in ocular area raised thus distorting the appearance of these organs. Chelicerae, maxillae and lip: apparently all essentially typical of females of the genus. Sternum: quite convex; longer than wide in ratio of about $7: 6$; fourth coxae separated by nearly I.33 times their width. Legs: essentially as in male; first femur with three long, ventral spines along promargin in distal half and probably two weak ventral spines on retromargin in distal half; first tibia with four pairs of ventral spines; first metatarsus probably with two pairs of ventral spines; second leg appears to bear ventral spines essentially like those on first leg but fragility of paratype prevents close observation. Abdomen: essentially typical of females of the ge.uus except for the scuta; dorsal scutum hardly discernible; ventral and epigastric scuta clearly visible and in general like those of other species in the genus; outlines of ventral scutum and epigynal area difficult to determine; center of the latter with the usual obscure pattern of small, twisted canaliculi.

Records. Because of some confusion in sorting there seems to be a slight uncertainty about the type locality and the locality from which a male paratype and a female paratype were obtained. As far as can be determined at the present time all three specimens were collected by Dr. W. L. Brown in Costa Rica, Río Toro Amarillo, near Guapiles, Heredia, March, 1966.

\section{Ischnothyreus indressus sp. nov.} Figures 13-20

Holotype. The male holotype is from Nevis, B. W. I. Sept. 2429, 1966. The name of the species is an arbiitrary combination of letters.

Description. Total length $1.58 \mathrm{~mm}$. Carapace $.75 \mathrm{~mm}$ long; $.6 \mathrm{~mm}$ wide; about $.24 \mathrm{~mm}$ tall; abruptly raised immediately behind PME; otherwise essentially as in I. peltifer (Simon). Eyes: six as usual in the genus; compactly arranged about as in I. peltifer (Simon); posterior row straight, viewed from above and measured by posterior borders. Ratio of eyes ALE : PME : PLE $=8: 7$ : 7. ALE separated only by a line; contiguous to PLE and separated 
from PME by about half their radius. PME contiguous and separated from PLE only by a line. Height of clypeus equal to about 5/8 of the diameter of ALE. Chelicerae: well developed; nearly vertical and parallel; fang normal, without such a basal knob as occurs in I. peltifer (Simon) and I. omus Suman; apparently without definite teeth along fang groove. Lip simple, without special modifications. Maxillae: convergent; modified distally (Fig. 13). Sternum: essentially as in $I$. peltifer (Simon); fourth coxae separated by 1.25 times their width. Legs and spines essentially as described for $I$. peltifer (Simon) by Dr. Petrunkevitch (1929) and Miss Bryant (1942). Palp: closely resembles this organ in I. peltifer (Simon) but with certain obscurely distinctive features (Figs. I4-I6). Abdomen: with dorsal scutum as in Figure 18 ; epigastric and ventral scuta not clear but, apparently, like those in I. peltifer (Simon); genital aperture as in Figure 17. Color in alcohol: essentially as described for I. peltifer (Simon) but somewhat lighter; oval areas on carapace somewhat darker than surrounding regions; palp typically dark brown.

Female paratype. Total length $2 . \mathrm{mm}$ including somewhat extended spinnerets and chelicerae. Carapace $.75 \mathrm{~mm}$ long; .64 $\mathrm{mm}$ wide; .3 I mm tall. Eyes: essentially as in male with minor variations. Chelicerae, maxillae, lip and sternum all essentially typical of females of the genus; no teeth observed along the fang groove. Legs and spines apparently also typical of females of the genus. Abdomen: with a well developed dorsal scutum (Fig. I9) ; epigastric and ventral scuta appear to be somewhat distinctive (Fig. 2O) but the epigynal area is poorly delineated.

Records. The described female paratype together with three additional female paratypes were taken on Nevis, B. W. I., Sept. 2429, 1966. One male was collected on St. Vincent, B. W. I., Oct. I5-24, I966; one male was taken on St. Thomas, U. S. V. I., February 14,1964 .

Bonnet, Pierre

\section{BIBLIOGRAPHY}

1957. Bibliographia Araneorum. Toulouse. Vol. 2(3).

BRyant, Elizabeth

1940. Cuban Spiders in the Museum of Comparative Zoology. Bull. Mus. Comp. Zool. 86(7): 249-532, 22 pls.

1942. Notes on the Spiders of the Virgin Islands. Bull. Mus. Comp. Zool., 89(7): 317-363, 3 pls.

1948. The Spiders of Hispaniola. Bull. Mus. Comp. Zool., 100 (4) : 331447,12 pls. 
Chickering, Arthur M.

1951. The Oonopidae of Panama. Bull. Mus. Comp. Zool., 106(5): 207-245, 31 figs.

Petrunkevitch, Alexander

1911. A synonymic index-catalogue of spiders of North, Central, South America, etc. Bull. Amer. Mus. Nat. Hist., 29: 1-809.

1928. Systema Araneorum. Trans. Connecticut Acad. Arts and Sci., 29: $1-270$.

1929. The Spiders of Porto Rico. Pt. 1. Trans. Connecticut Acad. Arts and Sci., 30:7-158, 150 figs.

ROEWER, C. Fr.

1942. Katalog der Araneae. 1: 1-1040. Bremen.

Simon, E.

1891. On the Spiders of the Island of St. Vincent. Pt. 1. Proc. Zool. Soc. of London, Nov. 17, 1891.

1892- Histoire naturelle des Araignées. Deuxième Edition. 2 Vols.

1903. Librarie Encyclopedique de Roret, Paris.

SUMAN, T. W.

1965. Spiders of the Family Oonopidae in Hawaii. Pacific Insects, $7(2): 225-242$. 

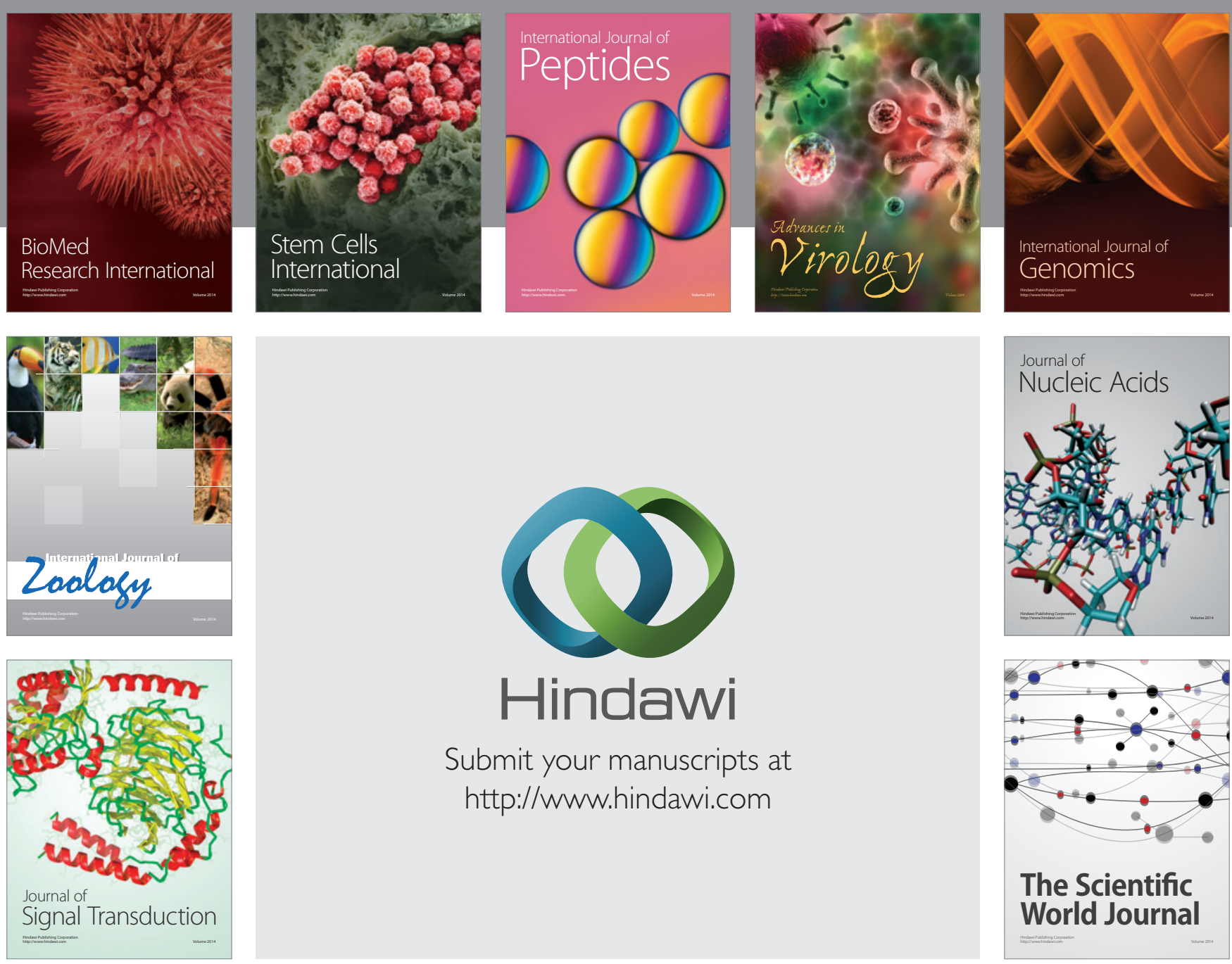

Submit your manuscripts at

http://www.hindawi.com
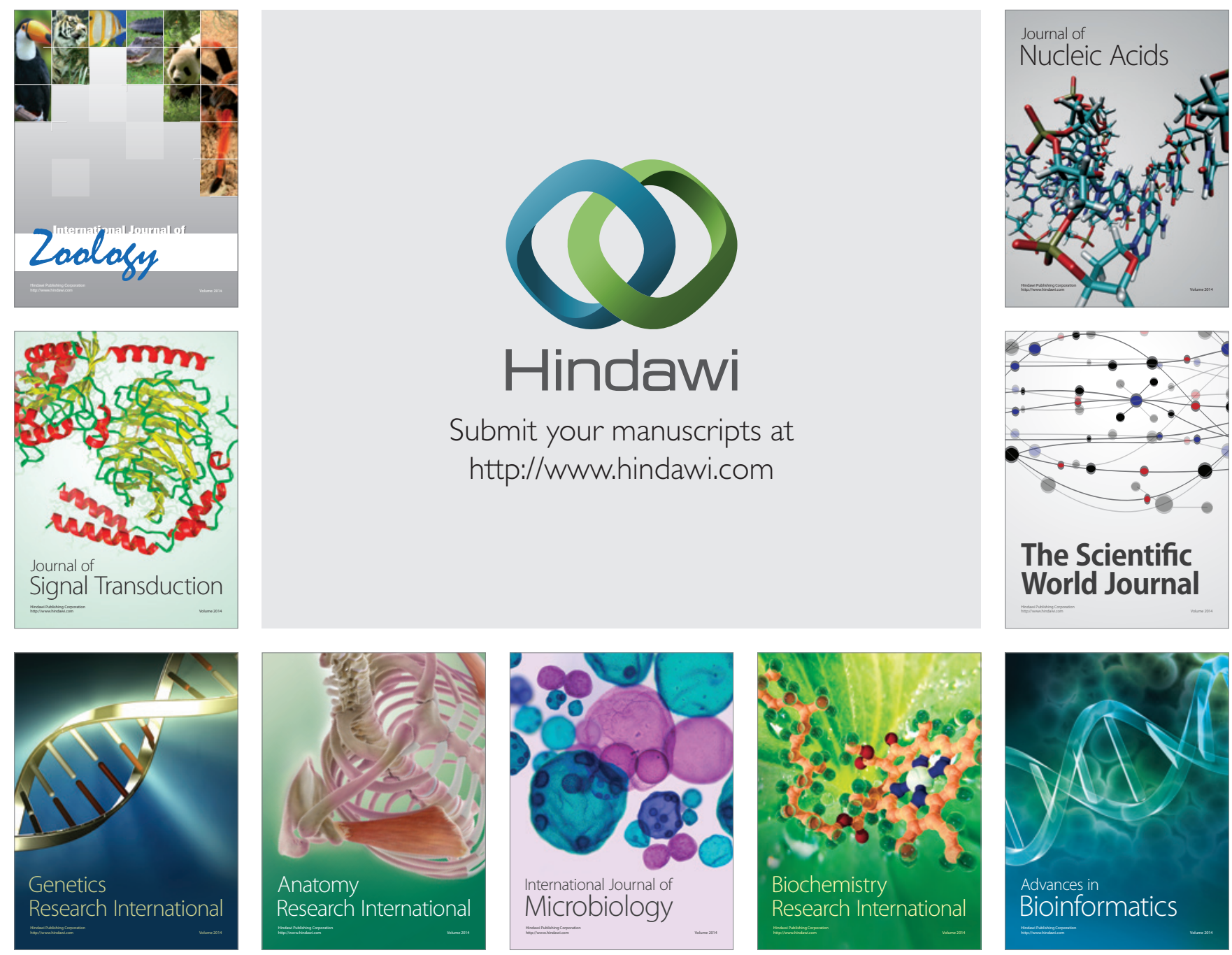

The Scientific World Journal
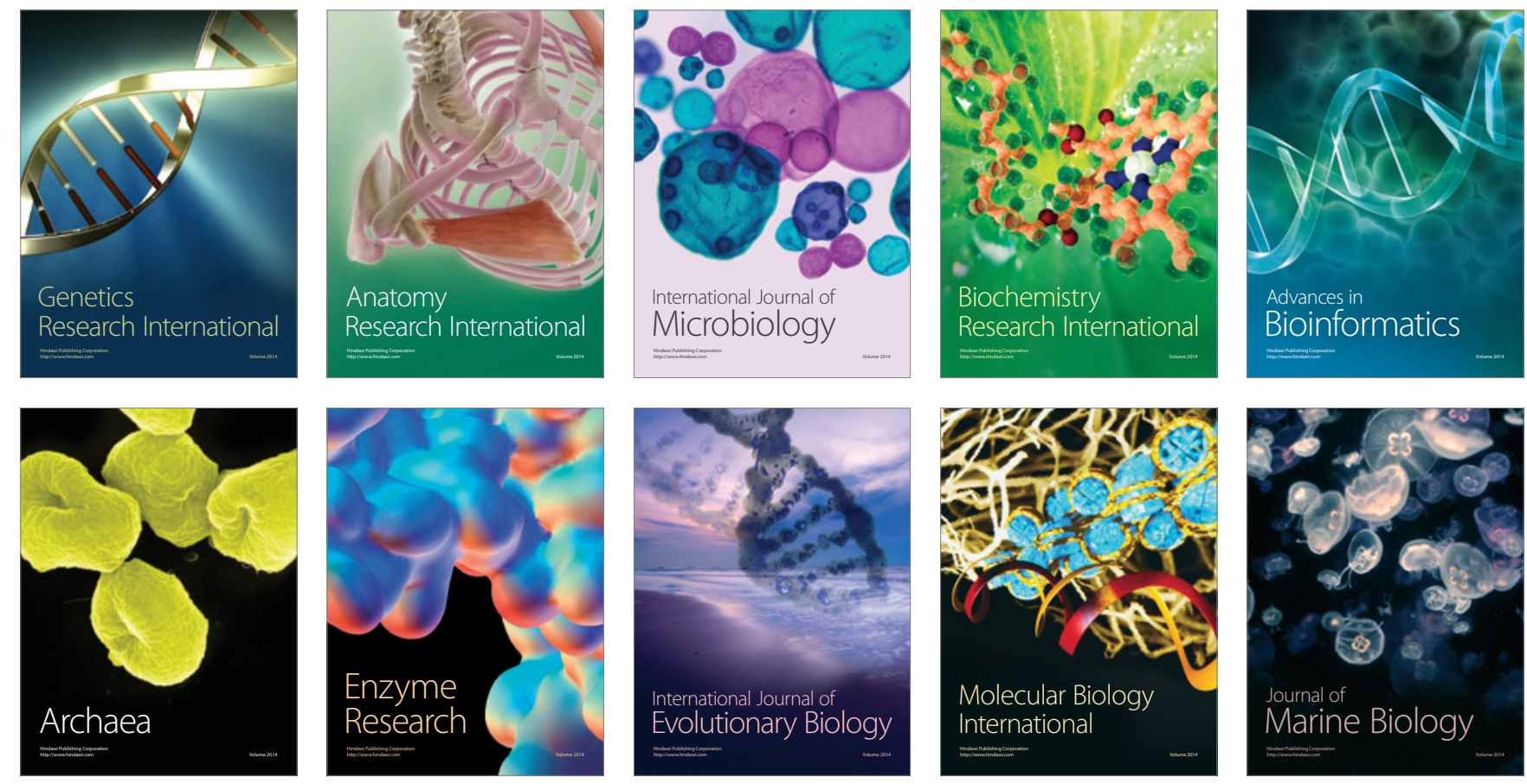